\title{
CYTOTOXIC POTENTIALS AND PHYTOCONSTITUENTS PROFILING OF BLEPHARIS EDULIS (FORSSK.) PERS. USING UHPLC/Q-TOF-MS-MS
}

\author{
Taha Abdel Maboud ${ }^{* 1}$, Mostafa M. Hegazy ${ }^{1}$, Abdel Salam Ebrahim ${ }^{1}$ and Lotfy D. \\ Ismail $^{1}$. \\ ${ }^{1}$ Department of Pharmacognosy, Faculty of Pharmacy, Al-Azhar University, Cairo, \\ Egypt.
}

*Corresponding author: TahaKedra.2@azhar.edu.eg

\begin{abstract}
Recently, the demand for discovery of safe anticancer drugs from nature has been extensively increased to avoid cancer chemotherapy side effects. Blepharis edulis (Forssk.) pers (Acanthaceae) is a perennial herb growing in Egypt with many traditional and pharmacological activities. The in vitro assay as well as identification of phytoconstituents in plant samples by LC/MS/MS spectrometry has reserve time and efforts for rapid screening and identification of biologically active compounds in plants. Herein, we investigated the cytotoxic activity of different fractions of Blepharis edulis methanolic extract using Sulforhodamine B stain (SRB) against three cancer cell lines; Hepatocellular carcinoma (HepG-2), human colon carcinoma (HCT-116), and human breast adenocarcinoma (MCF-7) cell lines. The results revealed that the $n$-butanol fraction showed the most potent cytotoxic activity against the three tested cancer cell lines with $\mathrm{CC}_{50}$ values $9.12 \pm 0.92,6.79 \pm 0.65$ and $4.19 \pm 0.51$ against MCF-7, HCT-116 and HepG2 cell lines, respectively. Moreover, the high resolution the ultra-highperformance liquid chromatography-quadrupole time-of-flight mass spectrometry (UHPLC/Q-TOF-MS-MS) metabolomic analysis for the $n$-butanol fraction as the most active sample has been achieved for the first time. A total of 3 - compound of different classes including flavonoids, aromatic aldehydes, aromatic acids and alkaloids, have been identified from Blepharis edulis.
\end{abstract}

Keywords: Blepharis edulis, Acanthaceae, cytotoxic activity, UHPLC/Q-TOF-MS-MS. 


\section{Introduction}

Cancer is a major public health problem all over the world and one of the major causes of death in developing countries, together with cardiac and cerebrovascular diseases (Ueda, Tezuka et al. 2002). Despite the great progress of cancer chemotherapy, the resulted side effects are still provoked and often severe causing patient incompliance (Schirrmacher 2019).Hence, the search for natural products to be used in cancer therapy represents an area of great interest in which the plant kingdom has been the most important source, providing many anti-tumor agents with novel structures and unique mechanisms of action (George, Bhalerao et al. 2010). Over 50\% of drugs used in clinical trials for anticancer activity have been isolated from natural sources or are related to them (George, Bhalerao et al. 2010). Blepharis is the largest genus of Acanthaceae comprises about 129 perennial herbs plants species widely distributed in India, Pakistan, Iran as well as Egypt (Vijayalakshmi and Kripa 2016). The plants are found in seasonally dry to arid habitats. Many species of Blepharis have been used in folk medicine as analgesic, in treatment of inflammation, and microbial infection and male impotence. There are many traditional uses for B. edulis as antiarthritic, antibacterial, antifungal, antioxidant, potent aphrodisiac and antispasmodic activities (Mundla and Sitaram 2013). Moreover, B. edulis is among the ingredients used in a herbal composition for vigor, vitality and general health tonic (Pande and Pathak 2009). Further, B. edulis revealed many biological activities as antioxidant (Ashour 2012, Mahboubi, Haghi et al. 2013), anti-inflammatory (kumar Duvey and Chowdhary 2016), aphrodisiac (Mathur and Sundaramoorthy 2009, Singh, Ali et al. 2013), antispasmodic, bronchodilator, antiplatelet aggregation (Saqib, Janbaz et al. 2012), antidiabetic, antihyperlipidemic (Kant, Dua et al. 2018), antileishmanial (de Sousa, Lima et al.), antibacterial and anti-fungal activities (Keymanesh, Hamedi et al. 2009). Recent investigations of genus Blepharis edulis revealed the presence of many phytochemical classes as, phenols, terpenoids, saponins, tannins, xanthoproteins. Alkaloids and flavonoid (Chatterjee, Sharma et al. 1990, HS and Leelavathi 2015). Currently, ultra-high performance liquid chromatography (UHPLC) combined with High-resolution mass techniques allows fast fingerprinting and identification of plant metabolomics including several flavonoids, coumarins, phenolic acids and terpenes in biological samples, medicinal plants and food (Echiburu-Chau, Pastén et al. 2017, Simirgiotis, Quispe et al. 2017). In the present work we aimed to profile the phytoconstituents of $B$. edulis most active cytotoxic fraction by the high resolution UHPLC/Q-TOF-MS-MS.

\section{Material and methods}

\section{Experimental section}

The analysis was carried out using an ExionLC Triple TOF 5600+ system (Sciex) operated at $40{ }^{\circ} \mathrm{C}$ and equipped with a Xbridge C-18 column (Waters, $3.5 \mu \mathrm{m}, 2.1 \mathrm{x} 50$ $\mathrm{mm}$ ), and precolumn (Phenomenex In-Line filter disks, $0.5 \mu \mathrm{m} \times 3.0 \mathrm{~mm}$ ). 


\section{Plant material}

Blepharis edulis aerial parts were collected at March 2017 from Al-Nakhl area in North Sinai, and kindly identified by Prof. Mohamed S. Tantawy, Professor of Plant Taxonomy, Faculty of Science, Ain-shams University. A voucher herbarium specimen had been deposited in the Department of Pharmacognosy, Faculty of Pharmacy, Al-Azher University, Nasr City, Cairo, Egypt.

\section{Extraction and fractionation}

Air-dried powdered aerial parts of B. edulis (980 g) were subjected to exhaustive extraction by percolation with aqueous $70 \% \mathrm{MeOH}(3 \times 4 \mathrm{~L})$. The combined methanolic extracts were concentrated under vacuum at $40{ }^{\circ} \mathrm{C}$ until dryness to obtain $130 \mathrm{~g}$ viscous residue. The dried extract was suspended in distilled water $(800 \mathrm{ml})$ and fractionated with different solvents to obtain $n$-hexane (10 g), dichloromethane (4 g), ethyl acetate ( $2 \mathrm{~g}), n$ butanol (20 g), and (80 g) aqueous fractions.

\section{Assay of cytotoxic activity}

Cell viability screening was carried out against three cancer cell lines; hepatocellular carcinoma (HepG-2), human colon carcinoma (HCT-116), and human breast adenocarcinoma (MCF-7) cell lines to determine 50\% Cytotoxic Concentration $\left(\mathrm{CC}_{50}\right)$. The cytotoxic activity was measured quantitatively using Sulforhodamine B stain (SRB) assay protocol (Skehan, Storeng et al. 1990, Vajrabhaya and Korsuwannawong 2018). Briefly, the cell lines were cultured in Dulbecco's Modified Eagle Medium (DMEM) media (Lonza group) supplemented with $200 \mathrm{mM}$ of L-glutamine and $10 \%$ of fetal bovine serum (FBS). The test fractions as well as astandard drug were dissolved in a mixture of Dimethyl Sulfoxide and Dulbecco's Modified Eagle's Medium (DMEM) with ratio 4:100 (v/v), respectively. An initial dose of $(1 \mathrm{mg} / \mathrm{ml})$ was tested on different cell lines and sub sequenced by five more dilutions using two-fold dilution factor to obtain ( 0 , $6.25,12.5,25,50$ and $100 \mu \mathrm{g} / \mathrm{mL})$. Cells were seeded with a concentration of $(6 \times$ $10^{4}$ cell $/ \mathrm{ml}$ ) for 24 hours in the flat bottom 96 well plates and incubated at $37{ }^{\circ} \mathrm{C}$ with $5 \%$ $\mathrm{CO}_{2}$ until semi confluent cell layer was obtained then, treated with $100 \mu \mathrm{l}$ of each of serially diluted compounds. After 48 hours, the anticancer activity of the tested samples was measured quantitatively by ELISA microplate reader at wave length $520 \mathrm{~nm}$ according to SRB assay protocol. All experiments were carried out in triplicate. The $\mathrm{CC}_{50}$ was calculated from the relation between surviving cells and drug concentration curve for each fraction using Sigmaplot software (Skehan, Storeng et al. 1990, Vajrabhaya and Korsuwannawong 2018).

\section{UHPLC/Q-TOF-MS-MS analysis}

The active fraction sample was analyzed at the Proteomics and Metabolomics lab, Cancer Children Hospital Egypt 57357, Cairo, Egypt and the sample was processed following Eissa et al procedure (Eissa, Hashim et al. 2020). Briefly, $50 \mathrm{mg}$ of the sample was dissolved in $1 \mathrm{~mL}$ of deionized water, methanol, and acetonitrile mixture in a ratio of 
50:25:25, respectively. The mixture was vortexed for 2 min followed by ultra-sonication for $10 \mathrm{~min}$ and centrifuged for $5 \mathrm{~min}$ at $10,000 \mathrm{rpm} .20 \mu \mathrm{l}$ stock $(50 / 1000 \mu \mathrm{l})$ was diluted with $1000 \mu \mathrm{l}$ reconstitution solvent to obtain finally $1 \mu \mathrm{g} / \mu \mathrm{l}$ injected concentration. $25 \mu \mathrm{l}$ of prepared sample was injected on a positive mode. The phytoconstituents of the fraction were analyzed by using UHPLC/Q-TOF-MS MS in positive mode. $10 \mu \mathrm{L}$ of the sample was injected and the used mobile phases were solvent A $(5 \mathrm{mM}$ ammonium format buffer $\mathrm{pH} 3$ containing 1\% methanol, and solvent $\mathrm{B}$ (100\% acetonitrile). The gradient elution at a Flow rate of $0.3 \mathrm{~mL} / \mathrm{min}$ was used as follow; isocratic $90 \%$ solvent $\mathrm{A}$ and $10 \% \mathrm{~B}(0-1$ min), linear from $90 \%$ to $10 \%$ solvent A $90 \%, 10 \%$ B to $10 \%$ A and $90 \%$ B (1.1-20.9 $\mathrm{min}$ ), isocratic $10 \%$ solvent $\mathrm{A}$ and $90 \% \mathrm{~B}(21-25 \mathrm{~min})$, and finally, isocratic $90 \%$ solvent $\mathrm{A}$ and $10 \% \mathrm{~B}(25.1-28 \mathrm{~min})$. The retention time and masses of the detected molecules were recorded by Peakview 2.2 software (SCIEX, USA) and MS-DIAL 3.70 software for data processing (Tsugawa, Cajka et al. 2015).

Many databases as Respect positive (2737 records), HDMB (Human Metabolome Database) and NIST (National Institute of Standards and Technology) libraries were used as references for the tentative identification of compounds. The identification was based on comparing their masses and fragmentation patterns with published compounds in literature.

\section{Results and discussion}

\section{Assessment of cytotoxic activity of different extracts}

Herein, in order to specify the most potent cytotoxic fraction of B. edulis, the total methanolic extract as well as different fractions were tested for its cytotoxic activity against MCF-7, HCT-116 and HepG2 cell lines using neutral red uptake assay. The 50\% cytotoxic concentration $\left(\mathrm{CC}_{50}\right)$ determined from the dose-response curve are shown in table 1.

The results revealed that the total methanolic extract and different fractions of $B$. edulis exhibited cytotoxic activity against the tested cell lines. The CC50 values against the different cancer cell lines (MCF-7, HCT-116 and HepG2) were ranged between 4.19 $\pm 0.51 \mu \mathrm{g} / \mathrm{mL}$ and $25.24 \pm 2.3 \mu \mathrm{g} / \mathrm{mL}$ which is acceptable level of plant extracts activity according to the National Cancer Institute (NCI) (Alonso-Castro, Villarreal et al. 2011).

Table 1: The $\mathrm{CC}_{50}$ values $(\mu \mathrm{g} / \mathrm{ml})$ of total methanolic extract and different fractions against the different cancer cell lines

\begin{tabular}{|c|l|c|c|c|}
\hline \multirow{2}{*}{ No. } & \multirow{2}{*}{ Tested sample } & \multicolumn{3}{|c|}{ Tested cell lines $(\mu \mathrm{g} / \mathrm{mL})$} \\
\cline { 3 - 5 } & & MCF-7 & HCT-116 & HepG2 \\
\hline 1 & TM & $25.24 \pm 2.3$ & $20.35 \pm 2.1$ & $18.27 \pm 1.9$ \\
\hline 2 & Hex & $15.32 \pm 1.57$ & $12.22 \pm 1.21$ & $7.52 \pm 0.82$ \\
\hline 3 & DCM & $10.78 \pm 1.1$ & $8.46 \pm 0.86$ & $6.25 \pm 0.66$ \\
\hline 4 & EtOAc & $17.23 \pm 1.68$ & $19.12 \pm 1.8$ & $15.19 \pm 1.52$ \\
\hline 5 & But & $9.12 \pm 0.92$ & $6.79 \pm 0.65$ & $4.19 \pm 0.51$ \\
\hline 6 & Dox & $4.63 \pm 0.30$ & $7.25 \pm 0.34$ & $3.56 \pm 0.61$ \\
\hline
\end{tabular}


TM, Total methanolic extract; Hex, $n$-Hexane fraction; DCM, Dichloromethane fraction, EtOAc, Ethyl acetate fraction; But, $n$-Butanol fraction; Dox, Doxorubicin.

Despite the high exhibited activity of hexane fraction against HepG2 (7.52 \pm 0.82$)$ and activity of dichloromethane fraction against HepG2 (6.25 \pm 0.66$)$ and HCT-116 (8.46 $\pm 0.86)$ while the $n$-butanol fraction showed the most potent cytotoxic activity against the three tested cancer cell line with $\mathrm{CC}_{50}$ values $9.12 \pm 0.92,6.79 \pm 0.65$ and $4.19 \pm 0.51$ against MCF-7, HCT-116 and HepG2 cell lines, respectively (Figure 1). further investigation using UPLC/Q-TOF-MS-MS technique was done to determine the constituents which may be responsible for the activity of $n$-butanol fraction.

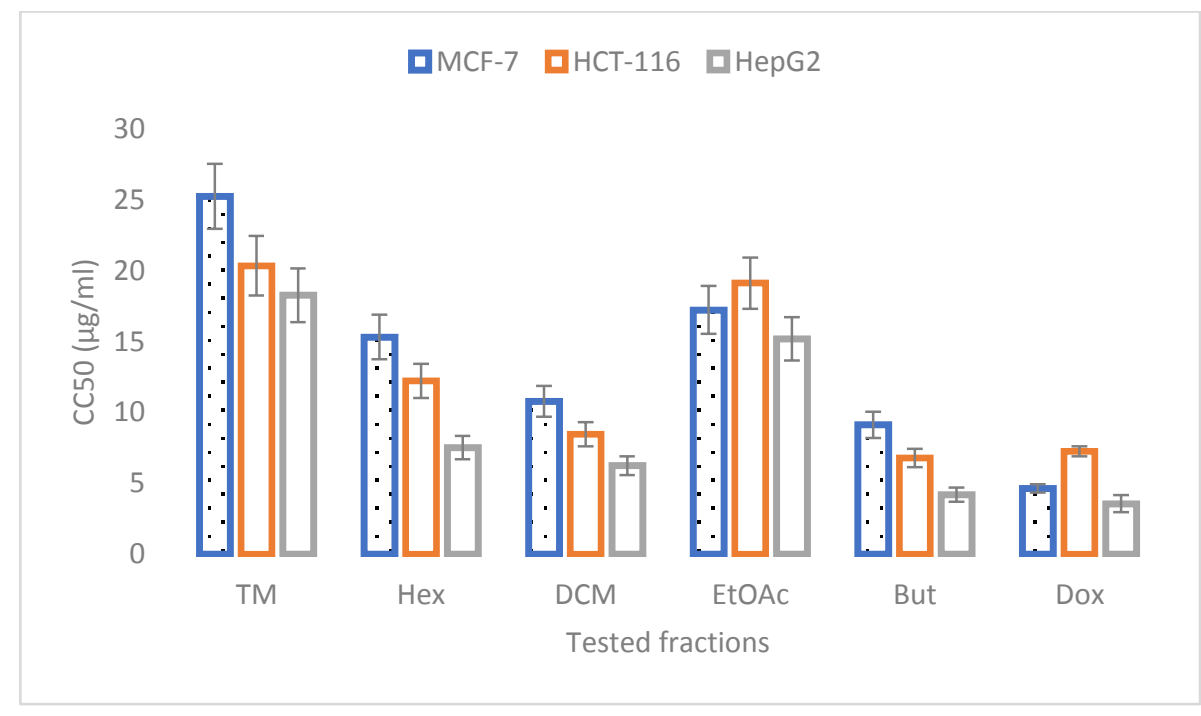

Figure 1: The $\mathrm{CC}_{50}$ values of different fractions against the different cancer cell lines

\section{Identification of active fraction phytoconstituents by UHPLC/Q-TOF-MS-MS}

Recently, LC/Q-TOF-MS-MS technique represents an important fast reliable approach to identifying the constituents of plant extracts (Wolfender, Queiroz et al. 2006). The phytochemical constituents of B. edulis $n$-butanol as potent cytotoxic fraction were analyzed via UHPLC/Q-TOF-MS-MS in positive ionization modes. A total of 30 identified peaks belong to different classes including flavonoids (flavanones, flavonols, flavones, Isoflavonoids, chalcones and anthocyanins), nitrogenous compounds (alkaloids), and aromatic aldehydes and acids were tentatively identified, as shown in Table 2. The base peak chromatogram (BPC) of the analyzed sample is shown in Figure2. 


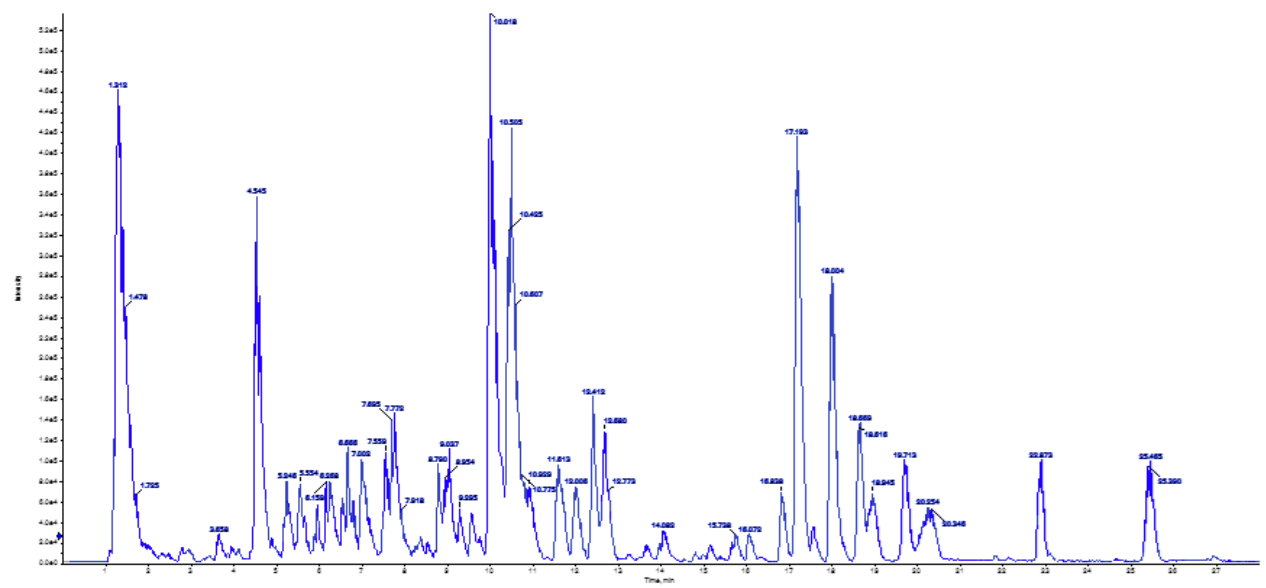

Figure 2: BPC of $n$-butanol fraction in positive ionization mode.

\section{Identification of flavonoids}

Most of identified compounds were flavonoids either $O$-glycosides (20 compounds) or aglycones (3 compounds) as protonated molecules $[\mathrm{M}+\mathrm{H}]{ }^{+}$. The flavonoid glycosides characterized by elimination of the sugar residue, that is, $176 \mathrm{amu}$ (hexuronic acid), 162 amu (hexose: glucose or galactose) and 146 amu (rhamnose) (Farag, El Fishawy et al. 2016). Fragmentation of flavonoid aglycones followed retro Diels-Alder (RDA) cleavage mechanism of C-ring also losing of 15, 18, 28 and 42 amu was commonly observed which representing $\left(\mathrm{CH}_{3}\right),\left(\mathrm{H}_{2} \mathrm{O}\right),(\mathrm{CO})$ and $\left(\mathrm{CH}_{2} \mathrm{CO}\right)$ respectively (Tsimogiannis, Samiotaki et al. 2007) as shown in the table 2 and figure 3

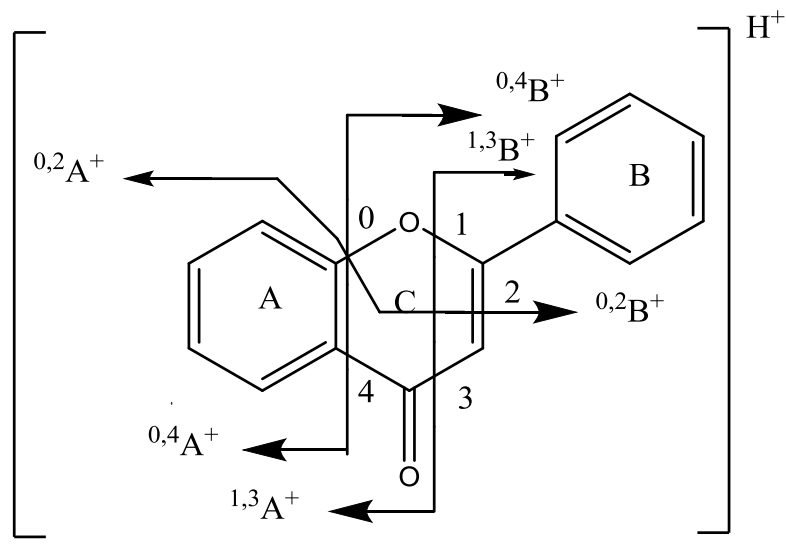

Figure 3: Schematic RDA diagram of ring $\mathrm{C}$ flavonoid, $\mathrm{A}$ and $\mathrm{B}$ represent the intact ring while the superscript on the left indicates the broken bonds of the protonated molecule.

The identified flavonoid constituents include flavones presented by compounds [apigenin-7- $O$-glucoside (11), diosmetin 7- $O$-rutinoside (13), baicalein-7- $O$-guluronide (16), diosmetin (26), and acacetin 7- $O$-neohespridoside (27)] and an isoflavone observed by compound biochanin A-7-O-glucoside (22) and flavanols identified compounds [isorhamnetin-3-O-rutinoside (2), Kaempferol-3- $O$-glucouronoid (8), eriodictyol-7-O- 
glucoside (9), Kaempferol-3,7-O-bis- $\alpha$-L-rahmnoside (14), and a Quercetin-4'- $O$ glucoside (19)] and flavanones presented by [eriodictyol-7- $O$-neohespridoside (7), and naringenin (20)] and anthocyanins identified by compounds [petunidin-3- $O$ - $\beta$-glucoside (6), pelargonidin-3,5- $O$ - di-glucoside (10), cyanidine-3- $O$-glucoside (12), malvidin-3$O$-glucoside (18), and cyanidine-3-O-rutinoside (24)] and chalcones detected by compounds [okanin-4'-O-glucoside (15), naringenin chalcone (17)] in addition to the aglycons which observed by compounds[luteolin (21), acacetin (29), apigenin (25)] (Figures 4)

\section{Identification of aromatic aldehydes and acids}

Investigation of the data revealed the presence of three aldehydes [cinnamaldehyde (1), syringaldehyde (5) and coniferaldehyde (23)] and two acids [caffeic acid (28) and trans-cinnamic acid (30)]. The neutral mass loss of hydroxyl, methyl, carboxylic, or aldehydic groups were helpful in identification as discussed in table 2 and figures $3 \& 4$.

\section{Identification of nitrogenous compounds:}

The analysis of a positive mode ESI results data revealed the presence of two alkaloids [Caffeine (3), and trigonelline (4)] were tentatively identified by comparison with previously published literature (Table 2, Figure 4). The analysis of the results showed that baicalein-7-O-glucuronide (16) was the major compounds with relative percent $(28.12 \%)$ followed by Malvidin-3-O-glucoside (18), $(23.84 \%)$. The previously published investigations of these compounds proved their anticancer activities against different of types cancer. baicalin (16) exhibited activity against prostate cancer cell lines (DU145) with $\mathrm{IC}_{50} 150 \mu \mathrm{M}$ by (MTT) assay method (Wang, Wang et al. 2018), while, malvidin-3-O-glucoside (18), exerts their effect on breast cancer cell line (MCF-7) with $\mathrm{IC}_{50} 109.08 \mu \mathrm{M}$ evaluated by SRB method (Oliveira, Wu et al. 2016). In addition, it was observed a promising activity against gastric cancer cell line (MKN-28) (Oliveira, Wu et al. 2016). This confirms that these compounds may be responsible for the cytotoxic activity of $n$-butanol fraction. 
Table 2: List of identified compounds from $n$-Butanol fraction of $B$. edulis

\begin{tabular}{|c|c|c|c|c|c|c|c|c|c|}
\hline No. & $\begin{array}{l}\text { Proposed } \\
\text { Compound }\end{array}$ & $\begin{array}{c}\text { Rt } \\
(\mathbf{m i} \\
\mathbf{n})\end{array}$ & $\begin{array}{l}\text { Relati } \\
\text { ve } \\
\text { percen } \\
\text { tage }\end{array}$ & $\begin{array}{c}\text { Precursor } \\
\mathbf{m} / z \\
\left(\mathbf{M S}^{1}\right) \\
\end{array}$ & $\begin{array}{l}\text { Adduct } \\
\text { Ion }\end{array}$ & $\begin{array}{l}\text { Chemical } \\
\text { Formula }\end{array}$ & $\begin{array}{l}\text { Error } \\
(\mathbf{p p m})\end{array}$ & $\begin{array}{c}\text { Characteristic } \\
\text { Fragments }\left(\mathbf{M S}^{2}\right)\end{array}$ & Ref \\
\hline 1 & $\begin{array}{c}\text { Cinnamalde } \\
\text { hyde }\end{array}$ & 3.42 & 0.0626 & 133.0626 & {$[\mathrm{M}+\mathrm{H}]^{+}$} & $\mathrm{C}_{9} \mathrm{H}_{9} \mathrm{O}^{+}$ & 10.9 & $105[\mathrm{M}+\mathrm{H}-\mathrm{CO}]^{+}$ & $\begin{array}{l}\text { (Mohammed, Khan et } \\
\text { al. 2021) }\end{array}$ \\
\hline 2 & $\begin{array}{c}\text { Isorhamneti } \\
\text { n-3-O- } \\
\text { rutinoside }\end{array}$ & 3.78 & 0.0914 & 625.1853 & {$[\mathrm{M}+\mathrm{H}]^{+}$} & $\underset{+}{\mathrm{C}_{28} \mathrm{H}_{33} \mathrm{O}_{16}}$ & -1 & $\begin{array}{l}317[\mathrm{M}+\mathrm{H}- \\
\text { rutinose }]^{+}\end{array}$ & $\begin{array}{l}\text { (Zhou, Tang et al. } \\
\text { 2014, Spínola, Pinto et } \\
\text { al. 2015, Hefny Gad, } \\
\text { Tuenter et al. 2018) }\end{array}$ \\
\hline 3 & Caffeine & 4.77 & 0.2540 & 195.0865 & {$[\mathrm{M}+\mathrm{H}]^{+}$} & $\underset{2^{+}}{\mathrm{C}_{8} \mathrm{H}_{11} \mathrm{~N}_{4} \mathrm{O}}$ & -0.4 & $\begin{array}{c}110[\mathrm{M}+\mathrm{H}-\text { methyl } \\
\text { isocyanate-CO }]^{+}, \\
138[\mathrm{M}+\mathrm{H}- \\
\text { methyl } \\
{\text { isocyanate }]^{+}}\end{array}$ & $\begin{array}{c}\text { (Ismail, Manickam et } \\
\text { al. 2000, Bianco, } \\
\text { Abate et al. 2009) }\end{array}$ \\
\hline 4 & Trigonelline & 5.75 & 0.6295 & 138.0552 & {$[\mathrm{M}+\mathrm{H}]^{+}$} & $\mathrm{C}_{7} \mathrm{H}_{8} \mathrm{NO}_{2}^{+}$ & -1.8 & $\begin{array}{c}79\left[\mathrm{M}+\mathrm{H}-\mathrm{CO}_{2-}\right. \\
\left.\mathrm{CH}_{3}\right]^{+}\end{array}$ & $\begin{array}{c}\text { (Lang, Yagar et al. } \\
\text { 2013, da Rosa, Freitas- } \\
\text { Silva et al. 2016) }\end{array}$ \\
\hline 5 & $\begin{array}{l}\text { Syringaldeh } \\
\text { yde }\end{array}$ & 6.35 & 0.2074 & 183.0924 & {$[\mathrm{M}+\mathrm{H}]^{+}$} & $\mathrm{C}_{9} \mathrm{H}_{11} \mathrm{O}_{4}^{+}$ & -0.1 & $\begin{array}{c}95[\mathrm{M}+\mathrm{H}- \\
\left.\mathrm{C}_{3} \mathrm{H}_{4} \mathrm{O}_{3}\right]^{+}, \\
168\left[\mathrm{M}+\mathrm{H}-\mathrm{CH}_{3}\right]^{+}\end{array}$ & $\begin{array}{l}\text { (Gioacchini, Roda et } \\
\text { al. 1996, Flamini, } \\
\text { Vedova et al. 2007, } \\
\text { Thiyam, Claudia et al. } \\
\text { 2009) }\end{array}$ \\
\hline 6 & $\begin{array}{l}\text { Petunidin-3- } \\
O \text { - } \beta \text { - } \\
\text { glucopyrano } \\
\text { side } \\
\end{array}$ & 6.51 & 2.1865 & 479.1165 & {$[\mathrm{M}]^{+}$} & $\underset{+}{\mathrm{C}_{22} \mathrm{H}_{23} \mathrm{O}_{12}}$ & 1.8 & $\begin{array}{c}302[\mathrm{M} \text {-glucose- } \\
\left.\mathrm{CH}_{3}\right]^{+}, 317[\mathrm{M}- \\
\text { glucose }]^{+}\end{array}$ & $\begin{array}{l}\text { (Faria, Marques et al. } \\
\text { 2011) }\end{array}$ \\
\hline 7 & $\begin{array}{c}\text { Eriodictyol- } \\
7-O- \\
\text { neohesperid } \\
\text { oside } \\
\text { (Neoeriocitr } \\
\text { in) }\end{array}$ & 6.54 & 0.7404 & 597.1531 & {$[\mathrm{M}+\mathrm{H}]^{+}$} & $\underset{+}{\mathrm{C}_{27} \mathrm{H}_{33} \mathrm{O}_{15}}$ & 6.4 & $\begin{array}{c}288 \text { [aglycon] } \\
435[\mathrm{M}+\mathrm{H}- \\
\left.\mathrm{C}_{6} \mathrm{H}_{10} \mathrm{O}_{5}\right]^{+}\end{array}$ & $\begin{array}{l}\text { (Mencherini, Campone } \\
\text { et al. 2013, Spínola, } \\
\text { Pinto et al. 2015) }\end{array}$ \\
\hline 8 & $\begin{array}{c}\text { Kaempferol } \\
-3-O \text { - } \\
\text { Glucuronide }\end{array}$ & 6.75 & $\begin{array}{c}14.276 \\
5\end{array}$ & 463.0888 & {$[\mathrm{M}+\mathrm{H}]^{+}$} & $\underset{+}{\mathrm{C}_{21} \mathrm{H}_{19} \mathrm{O}_{12}}$ & -3 & $\begin{array}{c}153{ }^{1,3} \mathrm{~A}^{+}, 241 \\
{[\mathrm{M}+\mathrm{H}-\text { glucuronic }} \\
\left.\text { acid }-\mathrm{H}_{2} \mathrm{O}-\mathrm{CO}\right]^{+}, \\
259[\mathrm{M}+\mathrm{H}- \\
\text { glucuronic acid - } \\
\mathrm{CO}^{+}, 269[\mathrm{M}+\mathrm{H}- \\
\text { glucuronic acid - } \\
\left.\mathrm{H}_{2} \mathrm{O}\right]^{+}, 287 \\
{[\mathrm{M}+\mathrm{H} \text {-glucuronic }} \\
\text { acid }]^{+}\end{array}$ & $\begin{array}{c}\text { (Tsimogiannis, } \\
\text { Samiotaki et al. 2007) }\end{array}$ \\
\hline 9 & $\begin{array}{l}\text { Eriodictyol- } \\
7-O- \\
\text { glucoside }\end{array}$ & 6.82 & 0.3256 & 451.1225 & {$[\mathrm{M}+\mathrm{H}]^{+}$} & $\underset{+}{\mathrm{C}_{21} \mathrm{H}_{22} \mathrm{O}_{11}}$ & 0.1 & $\begin{array}{c}153^{1,3} \mathrm{~A}^{+} 163 \\
0,4 \mathrm{~B}^{+}, 179[\mathrm{M}+\mathrm{H}- \\
\text { glucose }-\mathrm{B}-\mathrm{ring}]^{+}, \\
289[\mathrm{M}+\mathrm{H}- \\
\text { glucose }^{+}\end{array}$ & $\begin{array}{c}\text { (Tsimogiannis, } \\
\text { Samiotaki et al. 2007, } \\
\text { Peng, Lin et al. 2019) }\end{array}$ \\
\hline 10 & $\begin{array}{l}\text { Pelargonidi } \\
\text { n-3,5- } O \text { - di- } \\
\text { glucoside }\end{array}$ & 6.87 & 0.7378 & 595.1636 & {$[\mathrm{M}]^{+}$} & $\underset{+}{\mathrm{C}_{27} \mathrm{H}_{31} \mathrm{O}_{15}}$ & 1.6 & $\begin{array}{c}271[\mathrm{M}- \\
2 \text { glucose }]^{+}, 433 \\
{[\mathrm{M}-\text { glucose }]^{+}}\end{array}$ & $\begin{array}{l}\text { (Faria, Marques et al. } \\
\text { 2011, Diretto, Jin et al. } \\
\text { 2019) }\end{array}$ \\
\hline 11 & $\begin{array}{l}\text { Apigenin-7- } \\
O \text {-glucoside }\end{array}$ & 6.88 & 0.3270 & 433.0893 & {$[\mathrm{M}+\mathrm{H}]^{+}$} & $\underset{+}{\mathrm{C}_{21}} \mathrm{H}_{21} \mathrm{O}_{10}$ & 0 & $\begin{array}{l}271\left[\mathrm{M}+\mathrm{H}_{-}^{-}\right. \\
\text {glucose }]^{+}\end{array}$ & $\begin{array}{l}\text { (Petreska, Stefkov et } \\
\text { al. 2011, Bergantin, } \\
\text { Maietti et al. 2017) }\end{array}$ \\
\hline 12 & $\begin{array}{l}\text { Cyanidin-3- } \\
\text { glucoside }\end{array}$ & 6.91 & 1.2231 & 449.109 & {$[\mathrm{M}]^{+}$} & $\underset{+}{\mathrm{C}_{21} \mathrm{H}_{21} \mathrm{O}_{11}}$ & -1.7 & 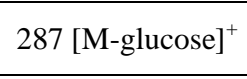 & $\begin{array}{l}\text { (Lopes-da-Silva, de } \\
\text { Pascual-Teresa et al. }\end{array}$ \\
\hline
\end{tabular}




\begin{tabular}{|c|c|c|c|c|c|c|c|c|c|}
\hline No. & $\begin{array}{l}\text { Proposed } \\
\text { Compound }\end{array}$ & $\begin{array}{c}\mathbf{R t} \\
(\mathbf{m i} \\
\mathbf{n})\end{array}$ & $\begin{array}{l}\text { Relati } \\
\text { ve } \\
\text { percen } \\
\text { tage }\end{array}$ & $\begin{array}{c}\text { Precursor } \\
\mathbf{m} / z \\
\left(\mathbf{M S}^{1}\right) \\
\end{array}$ & $\begin{array}{l}\text { Adduct } \\
\text { Ion }\end{array}$ & $\begin{array}{l}\text { Chemical } \\
\text { Formula }\end{array}$ & $\begin{array}{l}\text { Error } \\
(\text { ppm) }\end{array}$ & $\begin{array}{c}\text { Characteristic } \\
\text { Fragments }\left(\mathbf{M S}^{2}\right)\end{array}$ & Ref \\
\hline & $\begin{array}{c}\text { (Kuromanin } \\
\text { ) }\end{array}$ & & & & & & & & $\begin{array}{l}\text { 2002, Mena, Calani et } \\
\text { al. 2012) }\end{array}$ \\
\hline 13 & $\begin{array}{l}\text { Diosmetin } \\
7-O- \\
\text { rutinoside } \\
\text { (Diosmin) }\end{array}$ & 7.24 & 0.7930 & 609.1583 & {$[\mathrm{M}+\mathrm{H}]^{+}$} & $\underset{+}{\mathrm{C}_{28} \mathrm{H}_{33} \mathrm{O}_{15}}$ & -0.9 & $\begin{array}{l}463[\mathrm{M}+\mathrm{H}- \\
\text { rhamnose }^{+}\end{array}$ & $\begin{array}{c}\text { (Gattuso, Barreca et al. } \\
\text { 2007) }\end{array}$ \\
\hline 14 & $\begin{array}{c}\text { Kaempferol } \\
-3,7-O-\alpha- \\
\text { alpha-L- } \\
\text { rhamnoside }\end{array}$ & 7.26 & 0.4519 & 579.1415 & {$[\mathrm{M}+\mathrm{H}]^{+}$} & $\underset{+}{\mathrm{C}_{27} \mathrm{H}_{31} \mathrm{O}_{14}}$ & 4.7 & $\begin{array}{l}433[\mathrm{M}+\mathrm{H}- \\
\text { rhamnose }^{+}\end{array}$ & $\begin{array}{l}\text { (Ghareeb, Saad et al. } \\
\text { 2018, Santos, } \\
\text { Fortunato et al. 2019) }\end{array}$ \\
\hline 15 & $\begin{array}{l}\text { Okanin-4'- } \\
\text { O-glucoside } \\
\text { (Marein) }\end{array}$ & 7.29 & 0.3541 & 451.1671 & {$[\mathrm{M}+\mathrm{H}]^{+}$} & $\underset{+}{\mathrm{C}_{21} \mathrm{H}_{23} \mathrm{O}_{11}}$ & 11.9 & $\begin{array}{l}289[\mathrm{M}+\mathrm{H}- \\
\text { glucose }]^{+}\end{array}$ & $\begin{array}{l}\text { (Yang, Sun et al. 2016, } \\
\text { Peng, Lin et al. 2019) }\end{array}$ \\
\hline 16 & $\begin{array}{l}\text { Baicalein-7- } \\
\text { O- } \\
\text { glucuronide } \\
\text { (Baicalin) }\end{array}$ & 7.55 & $\begin{array}{c}28.120 \\
8\end{array}$ & 447.0919 & {$[\mathrm{M}+\mathrm{H}]^{+}$} & $\underset{+}{\mathrm{C}_{21} \mathrm{H}_{19} \mathrm{O}_{11}}$ & 0.3 & $\begin{array}{c}271[\mathrm{M}+\mathrm{H}- \\
\text { glucuronic acid }]^{+}\end{array}$ & $\begin{array}{c}\text { (Chung, Lim et al. } \\
\text { 2012) }\end{array}$ \\
\hline 17 & $\begin{array}{c}\text { Naringenin } \\
\text { chalcone }\end{array}$ & 7.73 & 4.6058 & 273.0728 & {$[\mathrm{M}+\mathrm{H}]^{+}$} & $\mathrm{C}_{15} \mathrm{H}_{13} \mathrm{O}_{5}^{+}$ & 8.1 & $\begin{array}{c}153\left[\mathrm{M}+\mathrm{H}^{-}\right. \\
\left.\mathrm{C}_{8} \mathrm{H}_{8} \mathrm{O}\right]^{+} \\
\end{array}$ & $\begin{array}{c}\text { (Wani, Pandith et al. } \\
\text { 2017) }\end{array}$ \\
\hline 18 & $\begin{array}{l}\text { Malvidin-3- } \\
O \text {-glucoside }\end{array}$ & 7.75 & $\begin{array}{c}23.847 \\
7\end{array}$ & 493.1318 & {$[\mathrm{M}]^{+}$} & $\underset{+}{\mathrm{C}_{23} \mathrm{H}_{25}} \mathrm{O}_{12}$ & 4 & $331{\left[\text { M-glucose }^{+}\right.}^{+}$ & $\begin{array}{c}\text { (Ştefănuţ, Căta et al. } \\
\text { 2011) }\end{array}$ \\
\hline 19 & $\begin{array}{c}\text { Quercetin- } \\
\text { 4'-glucoside } \\
\text { (Spiraeoside } \\
\text { ) }\end{array}$ & 7.96 & 1.5639 & 465.1359 & {$[\mathrm{M}+\mathrm{H}]^{+}$} & $\underset{+}{\mathrm{C}_{21} \mathrm{H}_{21} \mathrm{O}_{12}}$ & 0.8 & $\begin{array}{l}303[\mathrm{M}+\mathrm{H}- \\
\text { glucose }]^{+}\end{array}$ & $\begin{array}{c}\text { (Bonaccorsi, Caristi et } \\
\text { al. 2008) }\end{array}$ \\
\hline 20 & Naringenin & 8.99 & 0.2905 & 273.0749 & {$[\mathrm{M}+\mathrm{H}]^{+}$} & $\mathrm{C}_{15} \mathrm{H}_{13} \mathrm{O}_{5}^{+}$ & 2.5 & $\begin{array}{c}153\left[\mathrm{M}+\mathrm{H}^{-}\right. \\
\left.\mathrm{C}_{8} \mathrm{H}_{8} \mathrm{O}\right]^{+}\end{array}$ & $\begin{array}{l}\text { (Wani, Pandith et al. } \\
\text { 2017, Peng, Lin et al. } \\
\text { 2019) }\end{array}$ \\
\hline 21 & Luteolin & 9.66 & 2.0681 & 287.0537 & {$[\mathrm{M}+\mathrm{H}]^{+}$} & $\mathrm{C}_{15} \mathrm{H}_{11} \mathrm{O}_{6}^{+}$ & 0.1 & $\begin{array}{c}135^{1,3} \mathrm{~B}^{+}, 153[\mathrm{M} \\
\left.+\mathrm{H}_{-} \mathrm{C}_{8} \mathrm{H}_{6} \mathrm{O}_{2}\right]^{+} \\
269\left[\mathrm{M}+\mathrm{H}-\mathrm{H}_{2} \mathrm{O}\right]^{+}\end{array}$ & $\begin{array}{l}\text { (Tsimogiannis, } \\
\text { Samiotaki et al. 2007, } \\
\text { Yang, Sun et al. 2016, } \\
\text { Peng, Lin et al. 2019) }\end{array}$ \\
\hline 22 & $\begin{array}{c}\text { biochanin A } \\
7-O- \\
\text { glucoside } \\
\text { (Sissotrin) } \\
\end{array}$ & 9.80 & 0.4987 & 447.1241 & {$[\mathrm{M}+\mathrm{H}]^{+}$} & $\underset{+}{\mathrm{C}_{22} \mathrm{H}_{23}} \mathrm{O}_{10}$ & -2 & $\begin{array}{c}270\left[\mathrm{M}+\mathrm{H}_{-}^{-}\right. \\
\text {glucose-CH}]^{+} \\
285[\mathrm{M}+\mathrm{H}- \\
\text { glucose }]^{+} \\
\end{array}$ & $\begin{array}{l}\text { (Stobiecki, Staszków } \\
\text { et al. 2010, Roriz, } \\
\text { Barros et al. 2014) }\end{array}$ \\
\hline 23 & $\begin{array}{c}\text { 4-Hydroxy- } \\
3- \\
\text { methoxycin } \\
\text { namaldehyd } \\
\text { e } \\
\text { (Coniferalde } \\
\text { hyde) } \\
\end{array}$ & $\begin{array}{c}10.3 \\
5\end{array}$ & 1.5369 & 179.0699 & {$[\mathrm{M}+\mathrm{H}]^{+}$} & $\mathrm{C}_{10} \mathrm{H}_{11} \mathrm{O}_{3}^{+}$ & -0.3 & $\begin{array}{c}119[\mathrm{M}+\mathrm{H}- \\
\left.\mathrm{CH}_{3} \mathrm{OH}-\mathrm{CO}\right]^{+}, \\
147[\mathrm{M}+\mathrm{H}- \\
\left.\mathrm{CH}_{3} \mathrm{OH}\right]^{+}\end{array}$ & $\begin{array}{l}\text { (Flamini, Vedova et al. } \\
\text { 2007) }\end{array}$ \\
\hline 24 & $\begin{array}{l}\text { Cyanidin-3- } \\
O \text {-rutinoside }\end{array}$ & $\begin{array}{c}10.3 \\
8\end{array}$ & 4.1634 & 595.1433 & {$[\mathrm{M}]^{+}$} & $\underset{+}{\mathrm{C}_{27} \mathrm{H}_{31} \mathrm{O}_{15}}$ & 0.8 & $287{\text { [M-rutinose }]^{+}}^{+}$ & $\begin{array}{c}\text { (Kallam, Appelhagen } \\
\text { et al. 2017) }\end{array}$ \\
\hline 25 & Apigenin & $\begin{array}{c}10.8 \\
4\end{array}$ & 3.6397 & 271.0585 & {$[\mathrm{M}+\mathrm{H}]^{+}$} & $\mathrm{C}_{15} \mathrm{H}_{11} \mathrm{O}_{5}^{+}$ & 2.6 & $\begin{array}{c}119^{1,3} \mathrm{~B}^{+}, 121 \\
0,2 \mathrm{~B}^{+}, 153{ }^{1,3} \mathrm{~A}^{+} \\
225\left[\mathrm{M}+\mathrm{H}-\mathrm{H}_{2} \mathrm{O}-\right. \\
\mathrm{CO}]^{+}\end{array}$ & $\begin{array}{c}\text { (Tsimogiannis, } \\
\text { Samiotaki et al. 2007) }\end{array}$ \\
\hline 26 & $\begin{array}{c}(3,5,7- \\
\text { trihydroxy- } \\
4 \text { '- } \\
\text { methoxyflav } \\
\text { one) } \\
\text { (Diosmetin) }\end{array}$ & $\begin{array}{c}11.1 \\
4\end{array}$ & 2.8812 & 301.0702 & {$[\mathrm{M}+\mathrm{H}]^{+}$} & $\mathrm{C}_{16} \mathrm{H}_{13} \mathrm{O}_{6}^{+}$ & 1 & $\begin{array}{c}153^{1,3} \mathrm{~A}^{+}, 229 \\
{\left[\mathrm{M}+\mathrm{H}-\mathrm{CH}_{3}-\mathrm{COH}-\right.} \\
\mathrm{CO}]^{+}, \quad 257 \\
{\left[\mathrm{M}+\mathrm{H}-\mathrm{CH}_{3^{-}}\right.} \\
\mathrm{COH}]^{+}\end{array}$ & $\begin{array}{c}\text { (Fridén and Sjöberg } \\
\text { 2014, Peng, Lin et al. } \\
\text { 2019) }\end{array}$ \\
\hline
\end{tabular}




\begin{tabular}{|c|c|c|c|c|c|c|c|c|c|}
\hline No. & $\begin{array}{c}\text { Proposed } \\
\text { Compound }\end{array}$ & $\begin{array}{c}\mathbf{R t} \\
(\mathbf{m i} \\
\mathbf{n})\end{array}$ & $\begin{array}{l}\text { Relati } \\
\text { ve } \\
\text { percen } \\
\text { tage }\end{array}$ & $\begin{array}{c}\text { Precursor } \\
\mathbf{m} / z \\
\left(\mathbf{M S}^{1}\right) \\
\end{array}$ & $\begin{array}{l}\text { Adduct } \\
\text { Ion }\end{array}$ & $\begin{array}{l}\text { Chemical } \\
\text { Formula }\end{array}$ & $\begin{array}{l}\text { Error } \\
(\text { ppm) }\end{array}$ & $\begin{array}{c}\text { Characteristic } \\
\text { Fragments }\left(\mathbf{M S}^{2}\right)\end{array}$ & Ref \\
\hline 27 & $\begin{array}{c}\text { Acacetin-7- } \\
O- \\
\text { neohesperid } \\
\text { oside } \\
\text { (Fortunellin } \\
\text { ) }\end{array}$ & $\begin{array}{c}11.7 \\
8\end{array}$ & 0.3369 & 593.1643 & {$[\mathrm{M}+\mathrm{H}]^{+}$} & $\underset{+}{\mathrm{C}_{28} \mathrm{H}_{33} \mathrm{O}_{14}}$ & -0.8 & $\begin{array}{c}285[\mathrm{M}+\mathrm{H}- \\
\text { neohesperidose }^{+} \\
431[\mathrm{M}+\mathrm{H}- \\
\left.\mathrm{C}_{6} \mathrm{H}_{10} \mathrm{O}_{5}\right]^{+}\end{array}$ & (Feng, Liu et al. 2014) \\
\hline 28 & Caffeic acid & $\begin{array}{c}12.6 \\
9\end{array}$ & 1.3625 & 181.1200 & {$[\mathrm{M}+\mathrm{H}]^{+}$} & $\mathrm{C}_{9} \mathrm{H}_{9} \mathrm{O}_{4}^{+}$ & 2.5 & $\begin{array}{c}145[\mathrm{M}+\mathrm{H}- \\
\left.2 \mathrm{H}_{2} \mathrm{O}\right]^{+}, 153 \\
{[\mathrm{M}+\mathrm{H}-\mathrm{CO}]^{+}, 163} \\
{\left[\mathrm{M}+\mathrm{H}-\mathrm{H}_{2} \mathrm{O}\right]^{+}}\end{array}$ & $\begin{array}{c}\text { (Wu, Ma et al. 2009, } \\
\text { Bergantin, Maietti et } \\
\text { al. 2017) }\end{array}$ \\
\hline 29 & Acacetin & $\begin{array}{c}13.8 \\
3\end{array}$ & 0.1245 & 285.0741 & {$[\mathrm{M}+\mathrm{H}]^{+}$} & $\mathrm{C}_{16} \mathrm{H}_{13} \mathrm{O}_{5}^{+}$ & 4.5 & $\begin{array}{c}153[\mathrm{M}+\mathrm{H}- \\
\left.\mathrm{C}_{9} \mathrm{H}_{8} \mathrm{O}\right]^{+}, 242 \\
{\left[\mathrm{M}+\mathrm{H}-\mathrm{CH}_{3}-\mathrm{CO}\right]^{+}}\end{array}$ & (Peng, Lin et al. 2019) \\
\hline 30 & $\begin{array}{l}\text { trans- } \\
\text { Cinnamic } \\
\text { acid }\end{array}$ & $\begin{array}{c}14.2 \\
6\end{array}$ & 2.2975 & 149.0221 & {$[\mathrm{M}+\mathrm{H}]^{+}$} & $\mathrm{C}_{9} \mathrm{H}_{9} \mathrm{O}_{2}^{+}$ & 4.3 & $121[\mathrm{M}+\mathrm{H}-\mathrm{CO}]^{+}$ & $\begin{array}{c}\text { (Sun, Liang et al. } \\
\text { 2007, Baeza, Sarriá et } \\
\text { al. 2016) }\end{array}$ \\
\hline
\end{tabular}




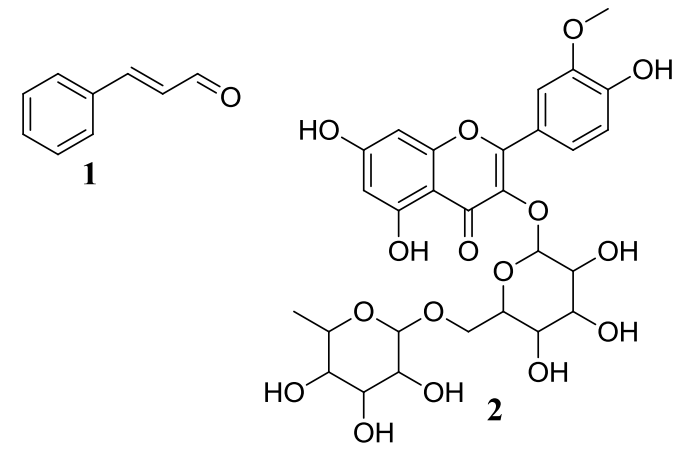<smiles>CC=C(C)/C(C)=C/C</smiles><smiles>CC(O)=C(C)O</smiles><smiles>Cn1c(=O)c2c(ncn2C)n(C)c1=O</smiles><smiles>CCCc1cc(OC)c(O)c(OC)c1</smiles><smiles>OCC1OC(OC2=CC(O)=Cc3[o+]c2c(OC2OC(CO)C(O)C(O)C2O)c(-c2ccc(O)cc2)[o+]3)C(O)C(O)C1O</smiles><smiles>CC(CO)C(O)C(C)C(=O)O</smiles><smiles>O=c1cc(-c2ccc(O)cc2)oc2cc(OC3OC(CO)C(O)C(O)C3O)cc(O)c12</smiles><smiles>OCC1OC(Oc2cc3c(O)cc(O)cc3[o+]c2-c2ccc(O)c(O)c2)C(O)C(O)C1O</smiles>

10<smiles>COc1ccc(-c2cc(=O)c3c(O)cc(OC4OC(COC5OC(C)C(O)C(O)C5O)C(O)C(O)C4O)cc3o2)cc1O</smiles><smiles>CC1OC(Oc2cc(O)c3c(=O)c(OC4OC(C)C(O)C(O)C4O)c(-c4ccc(O)cc4)oc3c2)C(O)C(O)C1O</smiles><smiles>O=C(/C=C/c1ccc(O)c(O)c1)c1ccc(OC2OC(CO)C(O)C(O)C2O)c(O)c1O</smiles>

15<smiles>O=C(O)C1OC(Oc2cc3oc(-c4ccccc4)cc(=O)c3c(O)c2O)C(O)C(O)C1O</smiles>

16

Figure 3: Structures of identified compounds (1-30) 
<smiles>COc1cc(-c2[o+]c3cc(O)cc(O)c3cc2OC2OC(CO)C(O)C(O)C2O)cc(OC)c1O</smiles><smiles></smiles><smiles>COc1cc(/C=C/C=O)ccc1O</smiles><smiles>O=c1cc(-c2ccc(O)cc2)oc2cc(O)cc(O)c12</smiles><smiles>COc1ccc(-c2cc(=O)c3c(O)cc(OC4OC(CO)C(O)C(O)C4OC4OC(C)C(O)C(O)C4O)cc3o2)cc1</smiles><smiles>COc1ccc(-c2cc(=O)c3c(O)cc(O)cc3o2)cc1</smiles><smiles>O=C(O)/C=C/c1ccccc1</smiles>

Figure 3: Structures of identified compounds (1-30) 


\section{Conclusion}

This study shed light on cytotoxic activities of different fractions of $B$. edulis methanolic extract against Human colon carcinoma (HCT-116), Human colon carcinoma (MCF-7) and Hepatocellular carcinoma $\left(\mathrm{HepG}_{2}\right)$ cell lines. Despite the different fractions showed promising activity, the n-butanol fraction was the most potent one. Metabolites profiling of the potent $n$-butanol fraction using UHPLC/Q-TOF-MS-MS analysis was conducted. The results analysis showed that baicalein-7- $O$-glucuronide and malvidin-3-Oglucoside were the major identified compounds. The promising results in the current study suggests further investigations for $B$. edulis phytochemicals and biological activities.

\section{REFERENCES}

Alonso-Castro, A. J., M. L. Villarreal, L. A. Salazar-Olivo, M. Gomez-Sanchez, F. Dominguez and A. Garcia-Carranca (2011). "Mexican medicinal plants used for cancer treatment: pharmacological, phytochemical and ethnobotanical studies." Journal of ethnopharmacology 133(3): 945-972.

Ashour, M. A.-G. (2012). "Isolation, HPLC/UV characterization and antioxidant activity of phenylethanoids from Blepharis edulis (Forssk.) Pers. growing in Egypt." Bulletin of Faculty of Pharmacy, Cairo University 50(1): 67-72.

Baeza, G., B. Sarriá, L. Bravo and R. Mateos (2016). "Exhaustive qualitative LC-DADMS $n$ analysis of arabica green coffee beans: cinnamoyl-glycosides and cinnamoylshikimic acids as new polyphenols in green coffee." Journal of agricultural and food chemistry 64(51): 9663-9674.

Bergantin, C., A. Maietti, A. Cavazzini, L. Pasti, P. Tedeschi, V. Brandolini and N. Marchetti (2017). "Bioaccessibility and HPLC-MS/MS chemical characterization of phenolic antioxidants in Red Chicory (Cichorium intybus)." Journal of Functional Foods 33: 94-102.

Bianco, G., S. Abate, C. Labella and T. R. Cataldi (2009). "Identification and fragmentation pathways of caffeine metabolites in urine samples via liquid chromatography with positive electrospray ionization coupled to a hybrid quadrupole linear ion trap (LTQ) and Fourier transform ion cyclotron resonance mass spectrometry and tandem mass spectrometry." Rapid Communications in Mass Spectrometry: An International Journal Devoted to the Rapid Dissemination of Up-to-the-Minute Research in Mass Spectrometry 23(7): 1065-1074.

Bonaccorsi, P., C. Caristi, C. Gargiulli and U. Leuzzi (2008). "Flavonol glucosides in Allium species: A comparative study by means of HPLC-DAD-ESI-MS-MS." Food Chemistry 107(4): 1668-1673. 
Chatterjee, A., N. Sharma, J. Banerji and S. Basa (1990). "Studies on Acanthaceae: Benzoxazine Glucoside and Benzoxazolone from Blepharis edulis Pers." ChemInform 21(21): no-no.

Chung, H.-J., S.-Y. Lim, I.-S. Kim, Y.-M. Bu, H.-C. Kim, D.-H. Kim and H.-H. Yoo (2012). "Simultaneous determination of baicalein, baicalin, wogonin, and wogonoside in rat plasma by LC-MS/MS for studying the pharmacokinetics of the standardized extract of Scutellariae Radix." Bulletin of the Korean Chemical Society 33(1): 177-182.

da Rosa, J. S., O. Freitas-Silva, J. R. C. Rouws, I. G. da Silva Moreira, F. J. M. Novaes, D. de Almeida Azevedo, N. Schwab, R. L. de Oliveira Godoy, M. N. Eberlin and C. M. de Rezende (2016). "Mass spectrometry screening of Arabica coffee roasting: a non-target and non-volatile approach by EASI-MS and ESIMS." Food Research International 89: 967-975.

de Sousa, G., W. G. Lima, F. J. dos Santos, F. A. Macías, J. María, G. Molinillo, R. G. Teixeira-Neto, J. M. de Siqueira and E. S. da Silva "Toxicity and Antipromastigote Activity of Benzoxazinoid Analogs Against Leishmania (Viannia) braziliensis and Leishmania (Leishmania) infantum."

Diretto, G., X. Jin, T. Capell, C. Zhu and L. Gomez-Gomez (2019). "Differential accumulation of pelargonidin glycosides in petals at three different developmental stages of the orange-flowered gentian (Gentiana lutea L. var. aurantiaca)." PloS one 14(2).

Echiburu-Chau, C., L. Pastén, C. Parra, J. Bórquez, A. Mocan and M. J. Simirgiotis (2017). "High resolution UHPLC-MS characterization and isolation of main compounds from the antioxidant medicinal plant Parastrephia lucida (Meyen)." Saudi Pharmaceutical Journal 25(7): 1032-1039.

Eissa, M. A., Y. Z. Hashim, D. M. El-Kersh, S. S. Abd-Azziz, H. M. Salleh, M. L. M. Isa and N. M. Abd Warif (2020). "Metabolite Profiling of Aquilaria malaccensis Leaf Extract Using Liquid Chromatography-Q-TOF-Mass Spectrometry and Investigation of Its Potential Antilipoxygenase Activity In-Vitro." Processes 8(2): 202.

Farag, M. A., A. M. El Fishawy, S. A. El-Toumy, K. F. Amer, A. M. Mansour and H. E. Taha (2016). "Antihepatotoxic effect and metabolite profiling of Panicum turgidum extract via UPLC-qTOF-MS." Pharmacognosy magazine 12(Suppl 4): S446. 
Faria, A. F., M. C. Marques and A. Z. Mercadante (2011). "Identification of bioactive compounds from jambolão (Syzygium cumini) and antioxidant capacity evaluation in different $\mathrm{pH}$ conditions." Food chemistry 126(4): 1571-1578.

Feng, X., Y. Liu, X. Wang and X. Di (2014). "Analysis of linarin and its metabolites in rat urine by LC-MS/MS." Chromatographia 77(7-8): 571-579.

Flamini, R., A. D. Vedova, D. Cancian, A. Panighel and M. De Rosso (2007). "GC/MSpositive ion chemical ionization and MS/MS study of volatile benzene compounds in five different woods used in barrel making." Journal of mass spectrometry 42(5): 641-646.

Fridén, M. E. and P. J. Sjöberg (2014). "Strategies for differentiation of isobaric flavonoids using liquid chromatography coupled to electrospray ionization mass spectrometry." Journal of Mass Spectrometry 49(7): 646-663.

Gattuso, G., D. Barreca, C. Gargiulli, U. Leuzzi and C. Caristi (2007). "Flavonoid composition of citrus juices." Molecules 12(8): 1641-1673.

George, S., S. V. Bhalerao, E. A. Lidstone, I. S. Ahmad, A. Abbasi, B. T. Cunningham and K. L. Watkin (2010). "Cytotoxicity screening of Bangladeshi medicinal plant extracts on pancreatic cancer cells." BMC Complementary and Alternative medicine 10(1): 52 .

Ghareeb, M., A. Saad, W. Ahmed, L. Refahy and S. Nasr (2018). "HPLC-DAD-ESIMS/MS characterization of bioactive secondary metabolites from Strelitzia nicolai leaf extracts and their antioxidant and anticancer activities in vitro." Pharmacognosy Research 10(4): 368.

Gioacchini, A. M., A. Roda, G. C. Galletti, P. Bocchini, A. C. Manetta and M. Baraldini (1996). "High-performance liquid chromatographic-electrospray mass spectrometric analysis of phenolic acids and aldehydes." Journal of Chromatography A 730(1-2): 31-37.

Hefny Gad, M., E. Tuenter, N. El-Sawi, S. Younes, E. M. El-Ghadban, K. Demeyer, L. Pieters, Y. Vander Heyden and D. Mangelings (2018). "Identification of some bioactive metabolites in a fractionated methanol extract from Ipomoea aquatica (aerial parts) through TLC, HPLC, UPLC-ESI-QTOF-MS and LC-SPE-NMR fingerprints analyses." Phytochemical Analysis 29(1): 5-15.

HS, N. and S. Leelavathi (2015). "Comparative antioxidant activity of whole plant of Blepharis maderaspatensis (L.) Heyne ex Roth. and Blepharis molluginifolia Pers. of Mysore district by DPPH method." Journal of Pharm Research 5(03). 
Ismail, M., E. Manickam, A. M. Danial, A. Rahmat and A. Yahaya (2000). "Chemical composition and antioxidant activity of Strobilanthes crispus leaf extract." The Journal of nutritional biochemistry 11(11-12): 536-542.

Kallam, K., I. Appelhagen, J. Luo, N. Albert, H. Zhang, S. Deroles, L. Hill, K. Findlay, Ø. M. Andersen and K. Davies (2017). "Aromatic decoration determines the formation of anthocyanic vacuolar inclusions." Current Biology 27(7): 945-957.

Kant, S., J. S. Dua and V. Lather (2018). "Investigation on anti-diabetic and antihyperlipidemic activities of Blepharis edulis root extract in wistar albino rats." Journal of Pharmacognosy and Phytochemistry 7(3): 2528-2534.

Keymanesh, K., J. Hamedi, S. Moradi, F. Mohammadipanah and S. Sardari (2009). "Antibacterial, antifungal and toxicity of rare Iranian plants." Int J Pharmacol 5(1): 81-85.

kumar Duvey, B. and Y. Chowdhary (2016). "A comprehensive list of plants used for antiinflammatory action." Indian Journal of Pharmaceutical and Biological Research 4(2): $52-59$.

Lang, R., E. F. Yagar, A. Wahl, A. Beusch, A. Dunkel, N. Dieminger, R. Eggers, G. Bytof, H. Stiebitz and I. Lantz (2013). "Quantitative studies on roast kinetics for bioactives in coffee." Journal of agricultural and food chemistry 61(49): 1212312128.

Lopes-da-Silva, F., S. de Pascual-Teresa, J. Rivas-Gonzalo and C. Santos-Buelga (2002). "Identification of anthocyanin pigments in strawberry (cv Camarosa) by LC using DAD and ESI-MS detection." European Food Research and Technology 214(3): 248-253.

Mahboubi, M., G. Haghi, N. Kazempour and A. R. Hatemi (2013). "Total phenolic content, antioxidant and antimicrobial activities of Blepharis edulis extracts." Songklanakarin Journal of Science \& Technology 35(1).

Mathur, M. and S. Sundaramoorthy (2009). "Plants with aphrodisiac potentials-the knowledge and the gaps." Indian Medicinal Plants. Aavishkar Publisher, Jaipur, India: 1-31.

Mena, P., L. Calani, C. Dall'Asta, G. Galaverna, C. García-Viguera, R. Bruni, A. Crozier and D. Del Rio (2012). "Rapid and comprehensive evaluation of (poly) phenolic compounds in pomegranate (Punica granatum L.) juice by UHPLCMSn." Molecules 17(12): 14821-14840. 
Mencherini, T., L. Campone, A. L. Piccinelli, M. García Mesa, D. M. a. Sánchez, R. P. Aquino and L. Rastrelli (2013). "HPLC-PDA-MS and NMR characterization of a hydroalcoholic extract of Citrus aurantium L. var. amara peel with antiedematogenic activity." Journal of agricultural and food chemistry 61(8): 1686-1693.

Mohammed, H. A., R. A. Khan, A. A. Abdel-Hafez, M. Abdel-Aziz, E. Ahmed, S. Enany, S. Mahgoub, O. Al-Rugaie, M. Alsharidah and M. S. Aly (2021). "Phytochemical Profiling, In Vitro and In Silico Anti-Microbial and Anti-Cancer Activity Evaluations and Staph GyraseB and h-TOP-II $\beta$ Receptor-Docking Studies of Major Constituents of Zygophyllum coccineum L. Aqueous-Ethanolic Extract and Its Subsequent Fractions: An Approach to Validate Traditional Phytomedicinal Knowledge." Molecules 26(3): 577.

Mundla, K. K. and B. Sitaram (2013). "Biological Activties, HPLC and NMR of Blepharis Glomerans." International Journal of Biological \& Pharmaceutical Research 4(6): 437-440.

Oliveira, H., N. Wu, Q. Zhang, J. Wang, J. Oliveira, V. de Freitas, N. Mateus, J. He and I. Fernandes (2016). "Bioavailability studies and anticancer properties of malvidin based anthocyanins, pyranoanthocyanins and non-oxonium derivatives." Food \& function 7(5): 2462-2468.

Pande, M. and A. Pathak (2009). "Investigation of aphrodisiac potential of Blepharis edulis Linn.(Utangan) claimed by tribals of Malwa region of Madhya Pradesh." Int J ChemTech Res 1(3): 769-776.

Peng, A., L. Lin, M. Zhao and B. Sun (2019). "Classification of edible chrysanthemums based on phenolic profiles and mechanisms underlying the protective effects of characteristic phenolics on oxidatively damaged erythrocyte." Food Research International 123: 64-74.

Petreska, J., G. Stefkov, S. Kulevanova, K. Alipieva, V. Bankova and M. Stefova (2011). "Phenolic compounds of mountain tea from the Balkans: LC/DAD/ESI/MSn profile and content." Natural product communications $6(1)$ : $1934578 X 1100600107$.

Roriz, C. L., L. Barros, A. M. Carvalho, C. Santos-Buelga and I. C. Ferreira (2014). "Pterospartum tridentatum, Gomphrena globosa and Cymbopogon citratus: A phytochemical study focused on antioxidant compounds." Food research international 62: 684-693.

Santos, M., R. H. Fortunato and V. G. Spotorno (2019). "Analysis of flavonoid glycosides with potential medicinal properties on Bauhinia uruguayensis and 
Bauhinia forficata subspecies pruinosa." Natural product research 33(17): 25742578.

Saqib, F., K. H. Janbaz, M. F. Latif, A. H. Gilani and S. Bashir (2012). "Ethnopharmacological studies on antispasmodic, bronchodilator and antiplatelet aggregation activities of Blepharis edulis pers." Asian J Nat Appl Sci 1: 1-9.

Schirrmacher, V. (2019). "From chemotherapy to biological therapy: A review of novel concepts to reduce the side effects of systemic cancer treatment." International journal of oncology 54(2): 407-419.

Simirgiotis, M. J., C. Quispe, A. Mocan, J. M. Villatoro, C. Areche, J. Bórquez, B. Sepúlveda and C. Echiburu-Chau (2017). "UHPLC high resolution orbitrap metabolomic fingerprinting of the unique species Ophryosporus triangularis Meyen from the Atacama Desert, Northern Chile." Revista Brasileira de Farmacognosia 27(2): 179-187.

Singh, R., A. Ali, G. Gupta, A. Semwal and G. Jeyabalan (2013). "Some medicinal plants with aphrodisiac potential: A current status." Journal of Acute Disease 2(3): 179-188.

Skehan, P., R. Storeng, D. Scudiero, A. Monks, J. McMahon, D. Vistica, J. T. Warren, H. Bokesch, S. Kenney and M. R. Boyd (1990). "New colorimetric cytotoxicity assay for anticancer-drug screening." JNCI: Journal of the National Cancer Institute 82(13): 1107-1112.

Spínola, V., J. Pinto and P. C. Castilho (2015). "Identification and quantification of phenolic compounds of selected fruits from Madeira Island by HPLC-DAD-ESIMSn and screening for their antioxidant activity." Food chemistry 173: 14-30.

Ştefănuţ, M. N., A. Căta, R. Pop, C. Moşoarcă and A. D. Zamfir (2011). "Anthocyanins HPLC-DAD and MS characterization, total phenolics, and antioxidant activity of some berries extracts." Analytical Letters 44(18): 2843-2855.

Stobiecki, M., A. Staszków, A. Piasecka, P. M. Garcia-Lopez, F. Zamora-Natera and P. Kachlicki (2010). "LC-MSMS profiling of flavonoid conjugates in wild Mexican lupine, Lupinus reflexus." Journal of Natural Products 73(7): 1254-1260.

Sun, J., F. Liang, Y. Bin, P. Li and C. Duan (2007). "Screening non-colored phenolics in red wines using liquid chromatography/ultraviolet and mass spectrometry/mass spectrometry libraries." Molecules 12(3): 679-693. 
Thiyam, U., P. Claudia, U. Jan and B. Alfred (2009). "De-oiled rapeseed and a protein isolate: characterization of sinapic acid derivatives by HPLC-DAD and LC-MS." European Food Research and Technology 229(5): 825-831.

Tsimogiannis, D., M. Samiotaki, G. Panayotou and V. Oreopoulou (2007). "Characterization of flavonoid subgroups and hydroxy substitution by HPLCMS/MS." Molecules 12(3): 593-606.

Tsugawa, H., T. Cajka, T. Kind, Y. Ma, B. Higgins, K. Ikeda, M. Kanazawa, J. VanderGheynst, O. Fiehn and M. Arita (2015). "MS-DIAL: data-independent MS/MS deconvolution for comprehensive metabolome analysis." Nature methods 12(6): 523.

Ueda, J.-y., Y. Tezuka, A. H. Banskota, Q. Le Tran, Q. K. Tran, Y. Harimaya, I. Saiki and S. Kadota (2002). "Antiproliferative activity of Vietnamese medicinal plants." Biological and Pharmaceutical Bulletin 25(6): 753-760.

Vajrabhaya, L.-o. and S. Korsuwannawong (2018). "Cytotoxicity evaluation of a Thai herb using tetrazolium (MTT) and sulforhodamine B (SRB) assays." Journal of Analytical Science and Technology 9(1): 15.

Vijayalakshmi, S. and K. Kripa (2016). "Therapeutic uses of plants of genus BlepharisA systematic review." Int. J. Pharma Bio Sci 7: B236-B243.

Wang, Z.-L., S. Wang, Y. Kuang, Z.-M. Hu, X. Qiao and M. Ye (2018). "A comprehensive review on phytochemistry, pharmacology, and flavonoid biosynthesis of Scutellaria baicalensis." Pharmaceutical biology 56(1): 465-484.

Wani, T. A., S. A. Pandith, A. P. Gupta, S. Chandra, N. Sharma and S. K. Lattoo (2017). "Molecular and functional characterization of two isoforms of chalcone synthase and their expression analysis in relation to flavonoid constituents in Grewia asiatica L." PloS one 12(6).

Wolfender, J.-L., E. F. Queiroz and K. Hostettmann (2006). "The importance of hyphenated techniques in the discovery of new lead compounds from nature." Expert opinion on drug discovery 1(3): 237-260.

Wu, Z.-J., X.-L. Ma, D.-M. Fang, H.-Y. Qi, W.-J. Ren and G.-L. Zhang (2009). "Analysis of caffeic acid derivatives from Osmanthus yunnanensis using electrospray ionization quadrupole time-of-flight mass spectrometry." European Journal of Mass Spectrometry 15(3): 415-429.

Yang, Y., X. Sun, J. Liu, L. Kang, S. Chen, B. Ma and B. Guo (2016). "Quantitative and qualitative analysis of flavonoids and phenolic acids in snow chrysanthemum 
(Coreopsis tinctoria Nutt.) by HPLC-DAD and UPLC-ESI-QTOF-MS." Molecules 21(10): 1307.

Zhou, H., W. Tang, J. Zeng and C. Tang (2014). "Screening of terpene lactones and flavonoid glycosides in Gingko biloba capsule by UPLC-Orbitrap high resolution MS, with emphasis on isomer differentiation." J Food Nutr Res 2(7): 369-376.

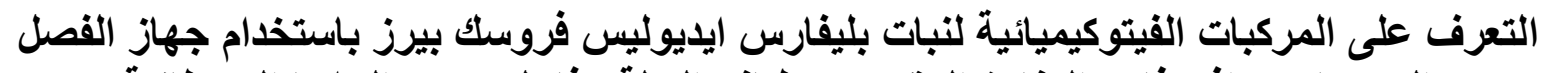

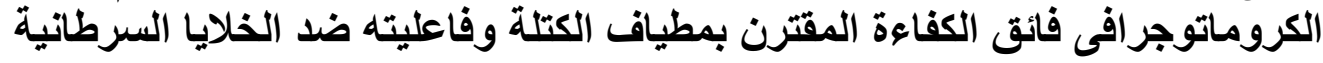

طه عبد المعبود'* ، مصطفى حجازى' ، عبد السلام ابر اهيم' ، لطفى دياب' 'قسم العقاقير ،كلية الصيدلة ،جامعة الاز هر ،القاهرة ،مصر

TahaKedra.2@azhar.edu.eg : البريد الاككتروني للباحث الرئيسي*

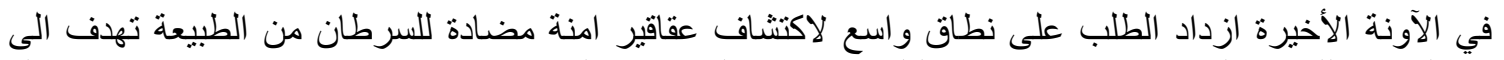

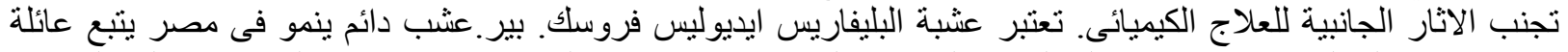

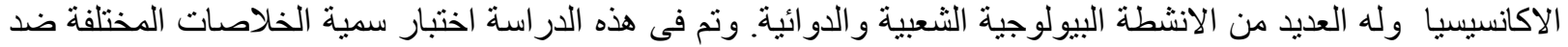

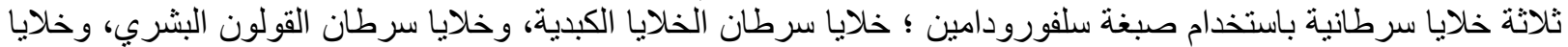

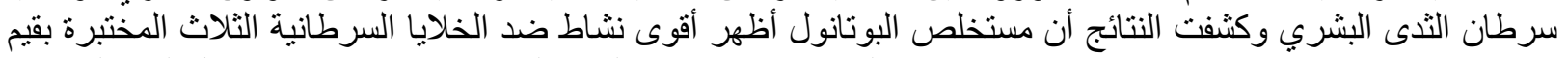

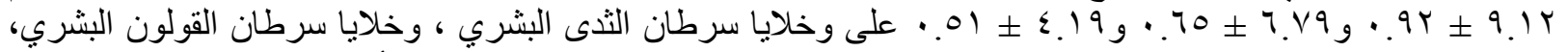

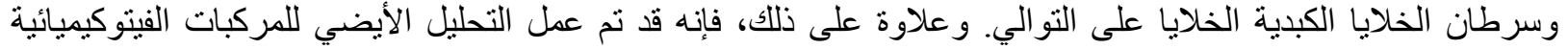

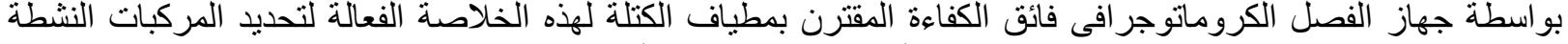

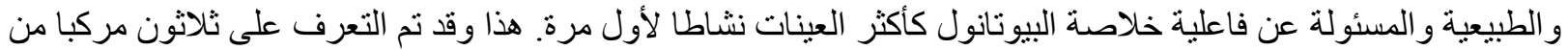

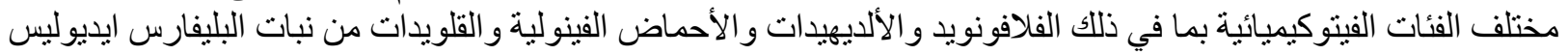

الكلمات المفتاحية : بليفارس ايديوليس ، اكانسيسيا ، النشاط السام للخلايا ، جهاز الفصل الكروماتوجر افى فائق الكفاءة المقترن بمطياف الكتلة 